\title{
Sustainable development of China's commercial vehicles
}

\author{
Li-Gang Wang $\cdot$ Ning Zhang
}

Received: 29 December 2014/ Accepted: 27 January 2015/Published online: 5 March 2015

(C) The Author(s) 2015. This article is published with open access at Springerlink.com

\begin{abstract}
Automobiles are the major contributor to fuel consumption and emission of pollutants. The growth of the vehicle fleet has also placed enormous pressure on China's energy supply and environment. Thus sustainable development of the Chinese automotive industry must pay significant attention to fuel-saving and emission-reduction of vehicles. Although commercial vehicles make up only about $20 \%$ of the entire automobile fleet, their contribution to energy-consumption and emission of pollutants is significant. Thus, priority should be given to fuel-saving and emission-reduction of commercial vehicles. As a result of concerted efforts by Chinese government, industry and enterprises, great progress has been made in technologies concerning new-energy, intelligent and lightweight automobiles. However, compared with developed countries, the level of lightweighting of commercial vehicles produced in China remains comparably low. This means that great potential for development of lightweight commercial vehicles in China exists and it will be an efficient path towards fuel-saving and emission-reduction.
\end{abstract}

Keywords Commercial vehicles · Fuel-saving · Emission-reduction $\cdot$ Lightweight

L.-G. Wang $(\bowtie) \cdot$ N. Zhang

Society of Automotive Engineers of China, Beijing 100055 ,

People's Republic of China

e-mail: wlg@sae-china.org

L.-G. Wang · N. Zhang

China Auto Lightweight Technology Innovation Strategic

Alliance, Beijing 100055, People's Republic of China

\section{Introduction}

The automotive industry plays a major role in fuel consumption and emission of pollutants. Yet its rapid growth in China in recent years has meant that the nation's energy supply and environment are under increasingly severe pressure. Commercial vehicles make up about $20 \%$ of China's total fleet of automobiles, but their considerable weight, high fuel consumption and long travel distances result in that they stand for nearly $50 \%$ of the total fuel consumption of all the automobiles in China [1]. Truck making represents only $17.5 \%$ of total production capacity for automobiles, while their particle emissions make up as much as $78.6 \%$ of the total automobile emission [2]. This is a serious problem. Therefore the sustainable development of China's automotive industry would not be possible without paying any attention to fuel-saving and emission-reduction.

\section{Current status of China's commercial vehicles with respect to fuel-saving and emission-reduction and future perspective}

According to the definitions provided in "Automobiles and Trailer Types-Terms and Definition" (GB/T 3730.12001), commercial vehicles are those with design and technical characteristics for the transportation of individuals and cargo, and can be classified into 5 types namely busses, trucks, semi-trailer towing vehicles, incomplete busses and incomplete trucks.

\subsection{Changes in commercial vehicle fleet in China}

Since 2005, the commercial vehicle fleet in China has grown rapidly along with increasing sales of automobiles. 
However, the ratio of the commercial vehicles to the total number of automobiles (excluding three-wheel vehicles and low-speed trucks) has gradually declined to around $20 \%$ [3] (see Fig. 1). In 2005, the total commercial vehicle fleet counted 10.272 million units, representing $32.5 \%$ of all the vehicles. After that, this share gradually declined. By 2010, the total commercial vehicle fleet counted 16.384 million units, representing $21 \%$ of all vehicles. By 2012 , the total commercial vehicle fleet counted 21.844 million units, representing $20 \%$ of all vehicles.

\subsection{Fuel consumption of Chinese commercial vehicles}

Since the beginning of the 21st century, there has been rapid growth in total fuel consumption in China. It grew from $8.9 \times 10^{7} \mathrm{t}$ in 2000 to $1.85 \times 10^{8} \mathrm{t}$ in 2009 , of which nearly $80 \%$ was accounted for by diesel and gasoline consuming automobiles [4] (see Fig. 2). Between 2000 and 2012, the automotive-related fuel consumption grew by a factor of 2.62 from $6.8 \times 10^{7} \mathrm{t}$ to $1.78 \times 10^{8} \mathrm{t}$ and an average annual growth rate of $8.36 \%$. This annual growth rate was far higher than the average annual growth rate $(6.5 \%)$ of total fuel consumption during the same period. Therefore, the automotive-related fuel consumption is a major factor for growth in China's total fuel consumption.

\subsection{Emission pollutants by Chinese commercial vehicles}

Between 2010 and 2012, the emissions of carbon monoxide $\left(\mathrm{CO}_{2}\right)$, hydrocarbons $(\mathrm{HC})$, nitrogen oxide $\left(\mathrm{NO}_{x}\right)$ and particulate matters (PM) emitted by automobiles in China have been steadily increasing (see Fig. 3). The emission of $\mathrm{CO}_{2}$ had increased from $2.67 \times 10^{7} \mathrm{t}$ to $2.87 \times 10^{7} \mathrm{t}$ at an average annual growth rate of $3.6 \%$; the emission of $\mathrm{HC}$ had increased from $3.24 \times 10^{6} \mathrm{t}$ to $3.45 \times 10^{6} \mathrm{t}$ at an average annual growth rate of $3.3 \%$; the emission of $\mathrm{NO}_{x}$ had increased from $5.37 \times 10^{6} \mathrm{t}$ to $5.83 \times 10^{6} \mathrm{t}$ with an average annual growth rate of $4.2 \%$; the emission of PM

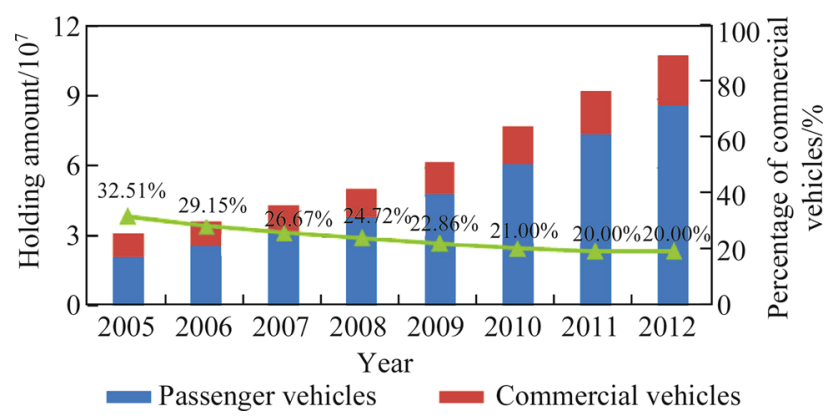

Fig. 1 Changes in total holdings of commercial vehicles in China since 2005 (Source: OICA website)

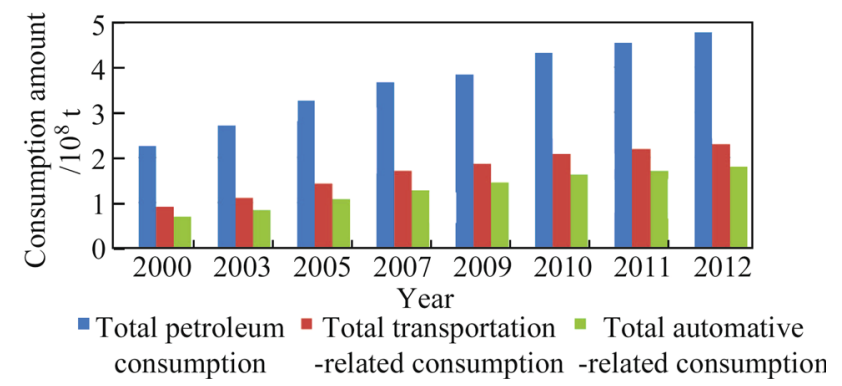

Fig. 2 Petrol consumption in China since 2000 (Source: "2014 Report on Development of China's Automotive Technology" by Society of Automotive Engineers of China)

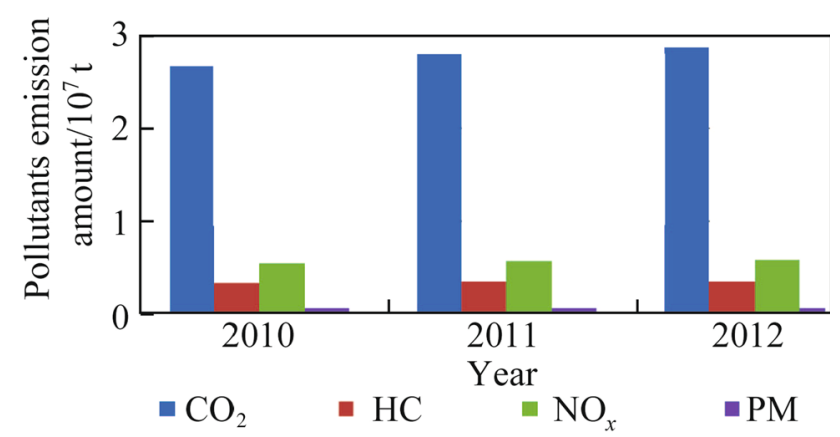

Fig. 3 Changing trends of pollutants emission by China automobiles (Source: "2013 Annual Report on Prevention and Treatment of Motor Vehicle Pollution in China" by the Ministry of Environmental Protection)

had increased from $0.57 \times 10^{6} \mathrm{t}$ to $0.59 \times 10^{6} \mathrm{t}$ at an average annual growth rate of $2.4 \%$.

With respect to pollutants emission by automobiles in 2012, the total emissions of $\mathrm{CO}_{2}, \mathrm{HC}, \mathrm{NO}_{x}$ and PM by trucks which made up only $17.5 \%$ of total holdings of automobiles (while also constituting $87.5 \%$ of the total commercial vehicle fleet) were $1.03 \times 10^{7} \mathrm{t}, 1.47 \times 10^{6} \mathrm{t}, 3.94 \times 10^{6} \mathrm{t}$, $0.47 \times 10^{6} \mathrm{t}$, respectively. Accordingly they represented $35.8 \%, 42.6 \%, 67.5 \%$ and $78.6 \%$ of the total $\mathrm{CO}_{2}, \mathrm{HC}, \mathrm{NO}_{x}$ and PM emissions, respectively.

\subsection{Future prospects of China commercial vehicles}

Although the automobile fleet in China has been growing with the increase in production and sales of automobiles, in 2012, the per capita ratio in this regard was only 79 vehicles per 1000 persons, which is nearly half of the average level of the world. This level was far lower than that in developed countries (500-800 vehicles per 1000 persons). It is quite conceivable that the Chinese automotive market, despite already being the largest in the world, continues to have enormous growth potential.

According to a relevant forecast [5], by 2020 and 2030 the total fleet of automobiles in China will respectively 
reach 250-290 million and 400-520 million. The growth rate for passenger vehicles is relatively fast and there exists some uncertainty. Passenger vehicles will reach 220-260 million and 350-480 million by 2020 and 2030, respectively, while the commercial vehicle fleet will grow to 33 million and 47 million, respectively.

Based on the above forecast it is safe to say that China's automotive products, in particular commercial vehicles, will bring severe pressure on the energy supply security and environmental-protection efforts. Therefore it is very important to adopt appropriate measures to achieve fuelsaving and emission-reduction by raising future technological level of commercial vehicles.

\section{Main emission-reduction measures relating to the automotive industry}

In recent years China's government, automotive industry and enterprises have been taking active steps to promote fuel-saving and emission-reduction.

For example, the Chinese government has issued a series of plans, policies and regulations to drive development of energy-saving and alternative-energy vehicles [6]. For example, "Development Plan for Energy-Saving and Alternative-Energy Vehicles (2012-2020)" (issued in 2012), "Twelfth Five-Year Plan Period on "Energy Development" (issued in 2013), "Action Plan for Preventing and Treating Atmospheric Pollution" (issued in 2013), "Energy Development Strategic Action Plan (2014-2020)" (issued in 2014 by the State Council), "Notice on Management of Fuel Consumption of Heavy Duty Commercial Vehicles" (jointly issued in 2012 by MIIT and Ministry of Communications), "Strengthening Coordination on 'Vehicles, Petrol and Road' and Expediting Proposal for Prevention and Treatment of Automobile Pollution" (jointly issued in October 2014 by CDRC, Ministry of Environmental Protection, MOST and MIIT, etc.), and a series of emission control standards were implemented over various stages (namely National Standard 1-5, etc.).

There also have been active initiatives by relevant organizations in the automotive industry. They exert their efforts through the establishment of technical development and technical exchange platforms as well as formulation of standards, etc. For example, the Society of Automotive Engineers of China (SAE-China) has played a leading role in the establishment of China Auto Lightweight Technology Innovation Strategic Alliance, Strategic Alliance for Innovation Electric Vehicle Industry and Strategic Alliance for Innovation in Telemetric Industry, as well as Technical Forum for China Automotive Lightweight and Conference on China Automotive Lightweight, etc. They have also formulated numerous technical specifications for alternative-energy vehicles and automotive lightweighting, along with the publication of numerous books covering this topic.

With the government support and active efforts by the industry, both car manufacturers and spare part enterprises have also taken active steps such as adjustments in their strategic planning, establishment of specialized branch companies (for examples the alternative-energy vehicle branch of the car companies) and increased investments in relevant research and development, in order to drive fuelsaving and emission-reduction.

In a word, Chinese government, the industry and enterprises are making great efforts in providing favorable conditions for the development of fuel-saving and alternativeenergy vehicles. They also provide strong impetus to continuous improvement in new-energy vehicle technology, ITenablement technology and lightweight technology.

\section{Lightweighting as an effective way to fuel-saving and emission-reduction for Chinese commercial vehicles}

Lightweighting is feasible under the conditions of cost control and performance improvement. Weight reduction can be achieved through lightweight design and technologies for integrated application, materials and advanced manufacturing [7]. Reduced weight for automobiles can significantly reduce fuel consumption and emissions. In a strategic forum on body engineering held in Germany, organized by Automotive Circle International in 2011, Fiat drew a conclusion after a comprehensive analysis: for every $10 \%$ reduction of a motor vehicle's weight, the fuel consumption can be reduced by $3.5 \%-6 \%$. Furthermore, there are differences in the relationship between the weight of an automobile and its fuel consumption under different road conditions. Thus, under certain conditions fuel consumption can be reduced by as much as $8 \%$. Correspondingly, the emission of carbon dioxide will be proportionately reduced, while the emission of other hazardous substances will be reduced by 5\%-6\%.

Overall, Chinese commercial vehicles are on average $10 \%$ heavier than similar-class foreign vehicles and key components such as vehicle frames and suspension springs are even heavier by $30 \%-40 \%$ [8]. The analysis results made by China Auto Lightweight Technology Innovation Strategic Alliance with respect to weight-reduction for Chinese heavy-duty trucks and tractors by using trailer/tractor ratio are showed as follows.

The coefficient of payload utilization is the ratio of a motor vehicle's payload mass to its tare mass, which can reflect the level of light-weighting of trucks and dumpers. 


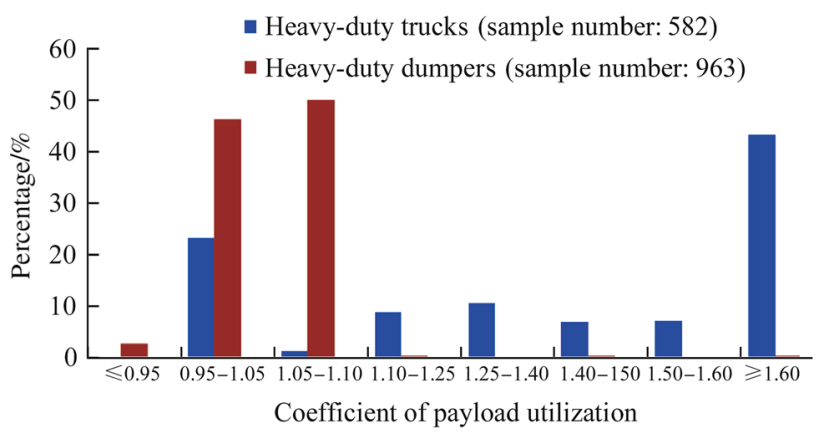

Fig. 4 Coefficient of payload utilization of Chinese trucks and dumpers (Source: Rearranged based on 226-229 public notices by China Auto Lightweight Technology Innovation Strategic Alliance in its "Automotive Manufacturers and Products" report)

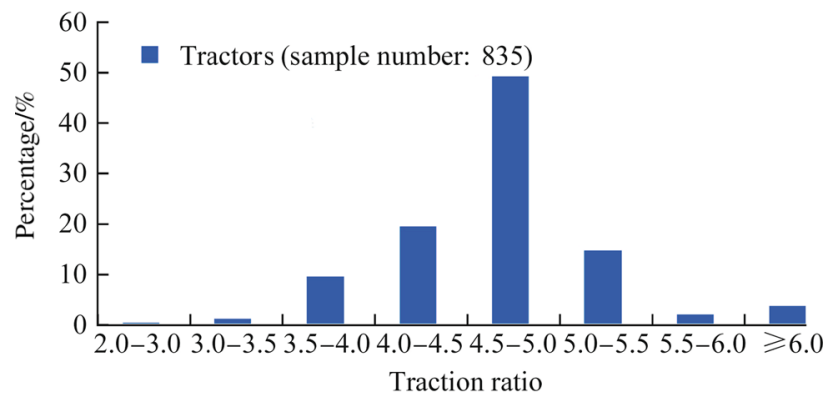

Fig. 5 Traction ratio of China tractors (Source: Rearranged based on 226-229 public notices by China Auto Lightweight Technology Innovation Strategic Alliance in its "Automotive Manufacturers and Products" report)

For trucks and dumpers with similar tare mass (tonnage), the greater coefficient of payload utilization would imply the higher level of automobiles' light-weighting, since they would be able to carry more cargos. By statistically analyzing 582 heavy-duty trucks and 963 heavy-duty dumpers based on 226-229 public notices in "Automotive Manufacturers and Products", it was found that over $96 \%$ of Chinese dumpers produced by indigenous brands had a coefficient of payload utilization of $0.95-1.1$, while only $43 \%$ of Chinese trucks had a coefficient of payload utilization exceeding 1.6 (see Fig. 4). In contrast, trucks and dumpers of foreign brands all had coefficients of payload utilization exceeding 1.6. In some cases it was as high as 1.75 (such as in the case of GAC Hino).

The traction ratio is the ratio of tractor's total mass and tare mass. It can reflect the level of tractors' lightweighting. For tractors with similar tare mass (tonnage), the bigger the traction ratio is, the more payloads the tractor could carry and a higher level of light-weighting the tractor has. By statistically analyzing 835 tractor models based on 226-229 public notices in "Automotive Manufacturers and Products", it was found that only $20 \%$ of Chinese indigenous heavy-duty tractors have a traction ratio exceeding 5.0 (see Fig. 5). In contrast, most tractors of foreign brands have a traction ratio above 5.2, some even reaching 6.93 (such as Mercedes Actros).

Based on the aforementioned analysis, there is great potential of lightweighting with respect to heavy-duty trucks, dumpers and tractors, which would be an effective means for fuel-saving and emission-reduction of Chinese commercial vehicles.

\section{Conclusions}

(i) China's automotive sales and fleet will continue to grow, but China's automotive industry must take into consideration the aspects of fuel-saving and emission reduction.

(ii) Although commercial vehicles make up only about $20 \%$ of the total automotive fleet in China, they significantly contribute to fuel consumption and emission of pollutants.

(iii) In recent years Chinese government, automotive industry and companies have been taking active steps to promote fuel-saving and alternativeenergy vehicles. The government has issued a series of energy-saving and emission-reduction policies to create a more favorable environment for automotive industries, which has helped the development of alternative-energy and lightweighting technologies of automobiles.

(iv) Compared with the foreign commercial vehicles, Chinese commercial vehicles still have great potential for lightweighting, which would be an effective means for energy-saving and emissionreduction.

Open Access This article is distributed under the terms of the Creative Commons Attribution License which permits any use, distribution, and reproduction in any medium, provided the original author(s) and the source are credited.

\section{References}

1. Zhang Yi, MIIT (2012) Setting limits on fuel consumption of heavy-duty commercial vehicles. China Secur J (A09)

2. Ministry of Environmental Protection (2013) Annual report on prevention and treatment of pollutant by automobiles. Ministry of Environmental Protection, Beijing

3. OICA (2014) World vehicles in use by country and type 2005-2012. http://www.oica.net/category/vehicles-in-use/. Accessed 27 December 2014

4. Society of Automotive Engineers of China (2014) 2014 report on development of automotive technology in China. Society of Automotive Engineers of China, Beijing 
5. Hao H, Wang HW, Ouyang MG (2011) Forecast on holdings of Chinese passenger vehicles and commercial vehicles. J Tsinghua Univ (Sci \& Technol) 51(6):868-872

6. Chinese Automotive Technology Research Centre, China Automotive Industry Association (2014) China automobile yearbook (2011-2014). China Automotive Industry Yearbook Publisher, Tianjin

7. Industrial Economy Research Department of Development Research Center of the State Council, Society of Automotive
Engineers of China, Volkswagen Group (China) (2011) 2011 report on development of China's automotive industry. Social Sciences Academic Press, Beijing, pp 238-323

8. Society of Automotive Engineers of China (2014) Strategic study report on development of lightweight technology for automobiles in China. Society of Automotive Engineers of China, Beijing 